\title{
Phytate: A Pharmacological Swiss Army Knife with Potential against Protein Glycation
}

\author{
Pilar Sanchis ${ }^{1}$ and Miquel Adrover ${ }^{1,2^{*}}$ \\ ${ }^{1}$ University Institute of Health Sciences (UNICS-IdisBa), Son Espases Hospital, Spain \\ ${ }^{2}$ Departament de Química, Universitat de les Illes Balears, Spain
}

Submission: June 19, 2017; Published: June 27, 2017

"Corresponding author: Miquel Adrover, University of Balearic Islands, Ctra. Valldemossa km 7.5, E-07122, Palma de Mallorca, Spain, Email: miquel.adrover@uib.es

\section{Opinion}

Myo-inositol hexaphosphate (phytate, IP6) is a natural compound used in the plant kingdom as a storage form of phosphorus. For instance, it stores $\sim 75 \%$ of total phosphorous in kernels [1], whereas this percentage is lower in tubers and roots $(\sim 0.1 \%)[2]$. As a result, seeds of many vegetables (but specially cereals, legumes or nuts) are the primary dietary sources of IP6 [3]. Consequently, the IP6 daily intake in humans varies from 0.18 to $4.57 \mathrm{~g}$, depending on the style diet (e.g. low in normal Western diets and high in vegetarian diets), and on the processing level of the food [3] since phytaseshydrolyze IP6 in food [4]. Between $37-66 \%$ of the dietary IP6 is degraded in the stomach during digestion when the diet is rich is phytases, but very limited in humans consuming diets with low phytase activity [5]. In any case, its hydrolysis rate strongly depends on the Ca level in diet [6], and it yields a large number of inositol phosphates that induce intracellular signal transduction function [7].

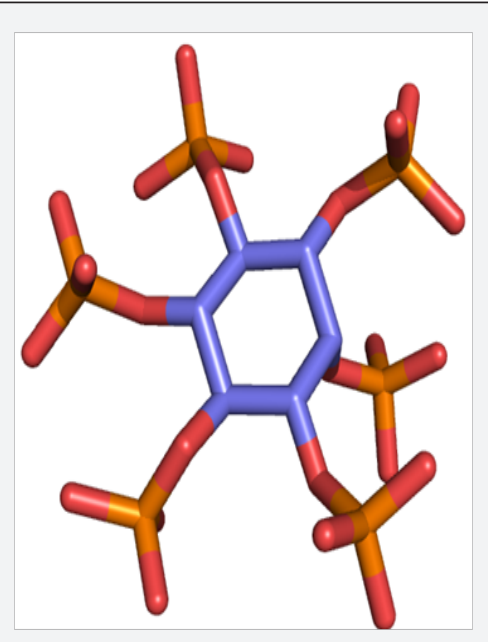

Figure 1: Stick representation of the three dimensional structure of IP6. Carbon atoms are colored in bue; oxygen atoms are colored in red; and phosphorus atoms are colored in orange.
IP6 is the hexaphosphoric ester of cyclohexane (Figure 1) and under physiological-like conditionsadopts a preferred chair conformation with 1 axial and 5 equatorial phosphate groups [8]. Eight out of the twelve hydroxyl groups carry negative charges, which together with its small size turns out IP6 into a molecule with high negative charge density. This suggests that IP6 should not be able to cross the lipid bilayer. However, Ferry et al. [10] found evidences of its internalization via pinocytosis [9], and different studies using 14C- and 3H-IP6 proved that it is absorbed and recovered in blood, organs (mainly in the cell cytosol), bones, urine and expired as $\mathrm{CO}_{2}[11,12]$. Consequently, and given that IP6-selective carriers have not yet been detected, its absorption is nowadays unexplainable [10]. The plasma concentration of IP6 in humans under a IP6-rich diet $(\sim 700 \mathrm{mg} /$ day $)$ was found to be $0.393 \pm 0.045 \mu \mathrm{M}$, whereas that decreased to $0.106 \pm 0.015 \mu \mathrm{M}$ under a diet low in IP6 $(<100 \mathrm{mg} /$ day). In any case, the absorption of IP6 is limited since diets including high amounts of IP6 $(\sim 3 \mathrm{~g} /$ day) did not result in significantly higher urinary excretion [13].

The negatively charged phosphate groups turn out IP6 into a potent metal chelator, especially of Fe, $\mathrm{Zn}, \mathrm{Mg}$ and $\mathrm{Ca}$ [14]. For instance, IP6 displaysa chelating activity towards Fehigher than EDTA or DFOA [15]. This let to consider IP6 as an antinutrient, since the formation of IP6-metal complexes was supposed to preclude their intestinal absorption causing $\mathrm{Ca}, \mathrm{Fe}$ or $\mathrm{Zn}$ deficiencies [16,17]. Contrarily, other studies indicated that the intake of high amounts of IP6 ( $\sim 2 \mathrm{~g} /$ day) in a balanced died had no adverse effects on mineral bioavailability $[18,19]$. In any case, the notorious chelating capacity of IP6 resulted into its application as a detoxifying agent against metals like $\mathrm{Cd}$ or $\mathrm{Pb}[20]$.

However, the most important pharmacological features of IP6 arise from its ability to bind Ca. Solubility of Ca salts in the urine are crucial for the formation of kidney stones, which are formed in $5-10 \%$ of people. Their formation mechanism starts 
with a nucleation process and the subsequent crystal growth [21]. Urine is supersaturated with respect to calcium oxalate, and depending on its $\mathrm{pH}$, it is also supersaturated with respect to calcium phosphate $(\mathrm{pH}>6.0)$. IP6 is naturally present in human urine $(0.5-3 \mathrm{mg} / \mathrm{l})$, although its concentration strongly depends on the dietary intake [22]. It was though that IP6 in urine could bind to crystal nuclei or crystal faces disturbing the crystal growth, as it was suggested during the $60 \mathrm{~s}$ for pyrophosphate [23] or bisphosphonates [24]. In fact, the administration of a rodent diet free of IP6 caused kidney calcification [25], while the administration of a diet rich in IP6 inhibited the interpapillary calcification [26]. In addition, it was shown that plasma IP6 was also able to inhibit the development of dystrophic calcifications [27]. Moreover, studies carried out on humans revealed that the ingestion of dietary IP6 reduced the risk to develop calcium stones, although the urinary lithogeny parameters were not modified [28]. All these results clearly proved that IP6 plays a crucial role as a crystallization inhibitor of Ca salts in kidney.

However, kidneys are not the only organs were pathophysiological calcifications occur. Salivary glands can also suffer calcifications. In fact, salivary Ca levels in patients with sialolithiasis were higher than those in healthy people, at the same time that their IP6 was lower. This let to assume that the absence of IP6 in saliva is an important factor of sialolith development [29]. Heart vessels can also suffer calcification through the formation of hydroxyapatite. This is generally caused by an initial injury, which acts as nucleant stimulating the subsequent crystal growth. Given its similarities with kidney calcifications, it was thought that IP6 would also be able to inhibit vascular calcifications. Indeed, IP6 decreased cardiovascular calcifications in rats subjected to calcinosis [30]. More recently, data collected from elderly patients proved that levels of urinary IP6 and mitral annulus calcification were inversely correlated, thus consumption of IP6-rich food might prevent cardiovascular calcification [31,32].

It is well known that crystallization inhibitors bindcrystal faces and disturb their growth. Besides this, their binding is also able to inhibit crystal dissolution, as it was proved for bisphosphonates on hydroxyapatite and on bone resorption [33]. Accordingly, it was observed that IP6 reduced bone mineral density loss due to estrogen deficiency in ovariectomized rats [34]. Moreover, studies carried out on patients revealed that bone mineral density increased directly with IP6 consumption, which suggested that IP6 could have a protective effect against osteoporosis [35]. Apart from that, IP6 may regulate physiologic bone mineralization by directly acting extracellularly, and by serving as a specific signal at the cellular level for the regulation of osteopontin gene expression [36]. All this data clearly suggests that IP6 could have a crucial role on bone mineralization and consequently, acts against osteoporosis.

A striking anticancer action of IP6 has been demonstrated on carcinogen-induced cancer models involving cancers of colon, liver, lung, mammary, prostate or skin. IP6 was able to reduce cell proliferation and differentiation of malignant cells. Preliminary studies in humans showed that IP6 enhanced the anticancer effect of chemotherapy and diminished the cancer metastases [37]. However, the exact mechanism through which IP6 ameliorates cancer is actually unknown and evidences suggesting a possible chelating-mediated mechanism are missing.

IP6 has also emerged as a powerful antioxidant. This is based on its capacity to chelate $\mathrm{Fe}$, which occurs through the three phosphate groups in positions 1, 2 and 3. These phosphate groups are flexible and bind the iron in the way that all six coordination sites are occupied by hydroxyl groups, thus yielding a highly stable complex (Kf 107) [38]. The formation of free radicals requires at least a free coordination site of Fe. Hence, the formation of the IP6-Fe complex, where Fe is fully chelated, inhibits the formation of $\mathrm{OH} \bullet$ radicals via de Fenton reaction [39].

The effectiveness of IP6 in all these cation-mediated pathologies suggests that IP6 could also be useful to treat other diseases where metals take an active role. One of them it could be the protein glycation, a non-enzymatic process responsible for the development of many diabetic-related diseases. Diabetes mellitus is an endocrine disorder characterized by chronic insulin resistance, which leads to hyperglycemia [40]. The enhanced levels of glucose induce disorders such as nephropathy [41], retinopathy [42] or dyslipidemia [43]. Although the exact molecular mechanisms through which hyperglycemia cause these diseases is not fully understood, one of the main triggering factors seems to be protein glycation and the consequent formation of a heterogeneous family of compounds, known as advanced glycation end products (AGEs) [44].

Protein glycation starts with the reaction between glucose and protein Lys side chains by forming a Schiff base that further rearranges into an Amadori product, which is the key factor that enables the final formation of AGEs through a metal-catalyzed mechanism.

Different mechanisms have been proposed by which AGEs could lead diabetic complications:

i) Accumulation in the extracellular matrix causing crosslinking [45];

ii) Binding to specific receptors (RAGEs) activating cell signaling pathways[46]; or

iii) Loss of protein function [47].

The direct involvement of AGEs in the development of diabeticrelated diseases has focused the therapeutic investigations towards the search of compounds capable to inhibit AGEs formation. Since metal-catalyzed reactions seem to play a major role in during the AGEs formation [48,49], chelation of $\mathrm{Fe}$ or $\mathrm{Cu}$ has emerged as an effective therapy. For instance, well recognized protein glycation inhibitors, such as pyridoxamine, carnosine, tenilsetam, OPB-9195 or LR-74 display a high affinity towards $\mathrm{Fe}$ and $\mathrm{Cu}$ [50-53]. This suggests that other compounds capable 
to bind $\mathrm{Cu}$ or Fe could also hold an important anti-glycating potential. As we mentioned before, IP6 is able to strongly chelate $\mathrm{Fe}$, a cation that plays a crucial role catalyzing the AGEs formation [54-56]. Therefore, this undoubtedly indicates that IP6 could acts as inhibitor of protein glycation and consequently, it could be effective as a therapy to prevent the development of some diabetes-related diseases. Moreover, it has been reported that IP6 intake reduces the blood levels of glucose [57]. Hence, if IP6 would be able to inhibit glycation, it would emerge as an effective therapy against diabetes mellitus giving its likely synergy between its potential as glycation inhibitor and as modulator of blood glucose levels.

So far, literature does not provide any insight on the possible effect of IP6 on the protein glycation nor on the AGEs formation. Given the preliminary data that mechanistically connects the chelating capacity of IP6 with the role of cations as catalyst of protein glycation, the investigation of IP6 as inhibitor of glycation is an issue that definitively demands an urgent attention. The obtained results, in case they would be positive, would pave a therapeutic platform for the future treatment of diabetic-related diseases.

\section{References}

1. Raboy V (2003) Myo-Inositol-1,2,3,4,5,6-hexakisphosphates. Phytochemistry 64(6): 1033-1043.

2. Phillippy BQ, Bland JM, Evens TJ (2003) Ion chromatography of phytate in roots and tubers. J Agric Food Chem 51(2): 350-353.

3. Schlemmer U, Frølich W, Prieto RM, Grases F (2009) Phytate in foods and significance for humans: Food sources, intake, processing, bioavailability, protective role and analysis. MolNutr Food Res 53(Suppl 2): 330-375.

4. Sandberg AS, Andlid T (2002) Phytogenic and microbial phytases in human nutrition. Int J Food Sci Technol 37: 823-833.

5. Sandberg AS, Andersson H (1988) Effect of dietary phytases on the digestion of phytate in the stomach and small intestine of humans. J Nutr 118(4): 469-473.

6. Sandberg AS, Larsen T, Sandström B (1993) High dietary calciumlevel decreases colonic phytate degradation in pigs fed a rapeseed diet. J Nutr 123(3): 559-566.

7. Schlemmer U, Jany KD, Berk A, Schulz E, Rechkemmer G (2001) Degradation of phytate in the gut of pigs - Pathway of gastro-intestinal inositol phosphate hydrolysis and enzymes involved. Arch AnimNutr 55(4): 255-280

8. Brigando C, Mossoyan JC, Favier F, Benlian D (1995) Conformational preferences and protonation sequence of myo-inositol hexaphosphate in aqueous solution; potentiometric and multinuclear magnetic resonance studies. J Chem Soc Dalton Trans pp. 575-578.

9. Ferry S, Matsuda M, Yoshida H, Hirata M (2002) Inositol hexakisphosphate blocks tumor cell growth by activating apoptotic machinery as well as by inhibiting the Akt/NFjB-mediated cell survival pathway. Carcinogenesis 23(12): 2031-3041.

10. Vucenik I, Shamsuddin AM (2006) Protection against cancer by dietary IP6 and inositol. Nutr Cancer 55(2): 109-125.

11. Nahapetian A, Young VR (1980) Metabolism of 14C-phytate in rats: effect of low and high dietary calcium intakes. J Nutr 110(7): 14581472 .
12. Sakamoto K, Vucenik I, Shamsuddin AM (1993) [3H] Phytic acid (inositol hexaphosphate) is absorbed and distributed to various tissues in rats. J Nutr 123(4): 713-720.

13. Grases F, Simonet BM, Vucenik I, Prieto RM, et al. (2001) Absorption and excretion of orally administered inositol hexaphosphate (IP6 or phytate) in humans. Biofactors 15(1): 53-61.

14. Vasca E, Materazzi S, Caruso T, Milano O, Fontanella C, Manfredi C (2002) Complex formation between phytic acid and divalent metal ions: a solution equilibria and solid state investigation. Anal BioanalChem 374(1): 173-178.

15. Hawkins PT, Poyner DR, Jackson TR, Letcher AJ, Lander DA, et al. (1993) Inhibition of iron-catalysed hydroxyl radical formation by inositol polyphosphates: a possible physiological function for myoinositol hexakisphosphate. Biochem J 294: 929-934.

16. Gibson RS, Bailey KB, Gibbs M, Ferguson EL (2010) A review of phytate, iron, zinc, and calcium concentrations in plant-based complementary foods used in low-income countries and implications for bioavailability. Food Nutr Bull 31(2 Suppl): 134-146.

17. Torre M, Rodriguez AR, Saura-Calixto (1991) Effects of dietary fiber and phytic acid on mineral availability. Crit Rev Food SciNutr 30(1): $10-22$.

18. Grases F, Simonet BM, Perello J, Costa-Bauzà A, Prieto RM (2004) Effect of phytate on element bioavailability in the second generation of rats. J Trace Elem Med Biol 17(4): 229-234.

19. Grases F, Simonet BM, Prieto RM, March JG (2001) Dietary phytate and mineral bioavailability. J Trace Elem Med Biol 15(4): 221-228.

20. Rose HE, Quarterman J (1984) Effects of dietary phytic acid on lead and cadmium uptake and depletion in rats. Environ Res 35(2): 482489.

21. Grases F, Costa-BauzaA (1999) Phytate (IP6) is a powerful agent for preventing calcifications in biological fluids: Usefulness in renal lithiasis treatment. Anticancer Res 19(5A): 3717-3722.

22. Grases F, Simonet BM, March JG, Prieto RM (2000) Inositol hexakisphosphate in urine: The relationship between oral intake and urinary excretion. Br J UrolInt 85(1): 138-142.

23. Fleisch H, Bisaz S (1962) Isolation from urine of pyrophosphate, a calcification inhibitor. Am J Physiol 203: 671-675.

24. Fleisch HA, Russell RGG, Bisaz S, Muhlbaue R, Williams DA (1970) Inhibitory effect of phosphonates on formation of calcium phosphate crystals in-vitro and on aortic and kidney calcification in-vivo. Eur J Clin Invest 1: 12-18.

25. Grases F, Prieto RM, Simonet BM, March JG (2000) Phytate prevents tissue calcifications in female rats. Biofactors 11: 171-177.

26. Grases F, Isern B, Sanchis P, Perello J et al. (2007) Phytate actsas an inhibitor in formation of renal calculi. Front Biosci 12: 2580-2587.

27. Grases F, Perello J, Prieto RM, Simonet BM, Torres JJ (2004) Dietary myo-inositol hexaphosphate prevents dystrophic calcifications in soft tissues: A pilot study in wistar rats. Life Sci 75(1): 11-19.

28. Conte A, Piza P, Garcia-Raja A, Grases F (1999) Urinary lithogen risk test: Usefulness in the evaluation of renal lithiasis treatment using crystallization inhibitors (citrate and phytate). Arch Esp Urol 52(1): 305-310.

29. Grases F, Santiago C, Simonet B M, Costa-Bauza A (2003) Sialolithiasis: Mechanism of calculi formation and etiologic factors. Clin Chim Acta 334(1-2): 131-136.

30. Grases F, Sanchis P, Perello J, Isern B, et al. (2007) Effect of crystalization inhibitors on vascular calcifications induced by vitamin d: A pilot study in Sprague-Dawley rats. Circ Res 71(7): 1152-1156. 
31. Fernández-Palomeque C, Grau A, Perelló J, Sanchis P, et al. (2015) Relationship between urinary level of phytate and valvular calcification in an elderly population: A cross-sectional study. PLoS One 10: e0136560.

32. Sanchis P, Buades JM, Berga F, Gelabert MM, Molina M, et al. (2016) Protective effect of myo-inositol hexaphosphate (phytate) on abdominal aortic calcification in patients with chronic kidney disease. J Ren Nutr 26(4): 226-236.

33. Fleisch H, Russell RGG, Francis MD (1969) Diphosphonates inhibit hydroxyapatite dissolution in vitro and bone resorption in tissue culture and in vivo. Science 165(3899): 1262-1266.

34. Grases F, Sanchis P, Prieto RM, Perelló J, López-González ÁA (2010) Effect of tetracalciumdimagnesiumphytate on bone characteristics in ovariectomized rats. J Med Food 13(6): 1301-1306.

35. López-González AA, Grases F, Monroy N, Marí B, Vicente-Herrero MT, et al. (2013) Protective effect of myo-inositol hexaphosphate (phytate) on bone mass loss in postmenopausal women. Eur J Nutr 52(2): 717 726

36. Addison WN, McKee MD (2010) Inositol hexakisphosphate inhibits mineralization of MC3T3-E1 osteoblast cultures. Bone 46(4): 11001107.

37. Vucenik I, Shamsuddin AM (2006) Protection against cancer by dietary IP6 and inositol. Nutr Cancer 55(2): 109-125.

38. Hawkins PT, Poyner DR, Jackson TR, Letcher AJ (1993) Inhibition of iron-catalysed hydroxyl radical formationby inositol polyphosphates: A possible physiological function for myo-inositol hexakisphosphate. Biochem J 294(1 pt 3): 929-934.

39. Rimbach G, Pallauf J (1998) Phytic acid inhibits free radical formation in vitro but does not affect liver oxidant or antioxidant status in growing rats. J Nutr 128(11): 1950-1955.

40. Lin Y, Sun Z (2010) Current views on type 2 diabetes. J Endocrinol 204(1): 1-11.

41. Chan GC, Tang SC (2016) Diabetic nephropathy: landmark clinical trials and tribulations. Nephrol Dial Transplant 31(3): 359-368.

42. Wong TY, Cheung CM, Larsen M, Sharma S, Simó R (2016) Diabetic retinopathy. Nat Rev Dis Primers 2: 16012.

43. Mooradian AD (2009) Dyslipidemia in type 2 diabetes mellitus. Nat Clin Pract Endocrinol Metab 5(3): 150-159.

This work is licensed under Creative Commons Attribution 4.0 License

DOI: 10.19080/CTBEB.2017.05.555667
44. Peppa M, Vlassara H (2005) Advanced glycation end products and diabetic complications: a general overview. Hormones 4: 28-37.

45. Aronson D (2003) Cross-linking of glycated collagen in the pathogenesis of arterial and myocardial stiffening of aging and diabetes. J Hypertens 21: 3-12.

46. Stern DM, Yan SD, Yan SF, Schmidt AM (2002) Receptor for advanced glycation endproducts (RAGE) and the complications of diabetes. Ageing Res Rev 1(1): 1-15.

47. Gomes RA, Oliveira LM, Silva M, Ascenso C (2008) Biochem J 416: 317 326.

48. Xiao H, Cai G, Liu M (2007) $\mathrm{Fe}^{2+}$-catalyzed non-enzymatic glycosylation alters collagen conformation during AGE-collagen formation in vitro. Arch BiochemBiophys 468: 183-192.

49. Hayase F, Shibuya T, Sato J, Yamamoto M (1996) Effects of oxygen and transition metals on the advanced Maillard reaction of proteins with glucose. Biosci Biotechnol Biochem 60(11): 1820-1825.

50. Price DL, Rhett PM, Thorpe SR, Baynes JW (2001) Chelating activity of advanced glycation end-product inhibitors. J BiolChem 276(52): 48967-48972

51. Peyroux J, Sternberg M (2006) Advanced glycation endproducts (AGEs): Pharmacological inhibition in diabetes. Pathol Biol 54(7): 405419.

52. Ortega-Castro J, Frau J, Casasnovas R, Fernández D, Donoso J, Muñoz F (2012) High- and low-spin Fe(III) complexes of various AGE inhibitors. J Phys ChemA 116: 2961-2971.

53. Ortega-Castro J, Adrover M, Frau J, Donoso J, Muñoz F (2008) Chelating power of LR-74, a new AGE-inhibitor. Chem Phys Lett 465: 120-125.

54. Sakurai T, Kimura S, Nakano M, Kimura H (1991) Oxidative modification of glycated low density lipoprotein in the presence of iron. BiochemBiophys Res Commun 177(1): 433-439.

55. Loske C, Gerdemann A, Schepl W, Wycislo M, Schinzel R, M, et al. (2000) Transition metal-mediated glycoxidation accelerates cross-linking of beta-amyloid peptide. Eur J Biochem 267(13): 4171-4178.

56. Kang JH (2003) Oxidative damage of DNA by the reaction of amino acid with methylglyoxal in the presence of Fe(III). Int J BiolMacromol 33(13): 43-48.

57. Lee SH, Park HJ, Chung HK, Cho SY (2006) Dietaryphytic acid lowers the blood glucose level in diabetic KK mice. Nutr Res 26: 474-479.

\section{Your next submission with Juniper Publishers will reach you the below assets}

- Quality Editorial service

- Swift Peer Review

- Reprints availability

- E-prints Service

- Manuscript Podcast for convenient understanding

- Global attainment for your research

- Manuscript accessibility in different formats

( Pdf, E-pub, Full Text, Audio)

- Unceasing customer service

Track the below URL for one-step submission https://juniperpublishers.com/online-submission.php 